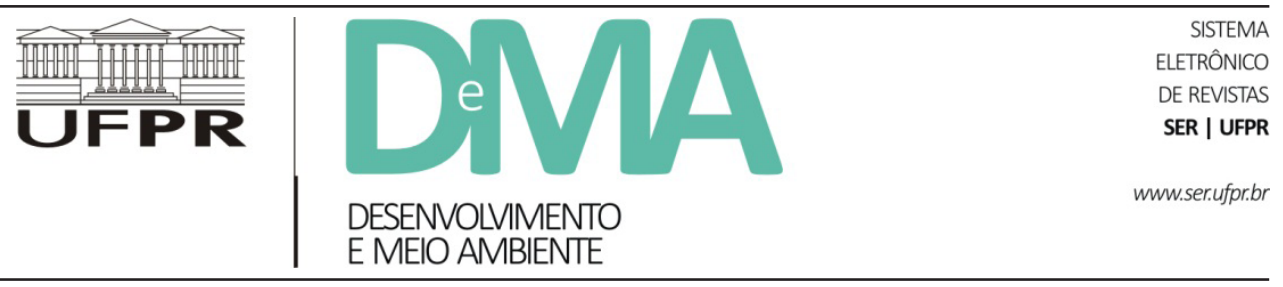

\title{
Estudo exploratório sobre o comportamento de consumo e de descarte das tecnologias digitais por jovens
}

\section{Exploratory Study of Consumer Behavior and Disposal of Digital Technologies by Youngsters}

\author{
Eduardo Chierrito de ARRUDA ${ }^{1}$, Wellington Francisco BESCOROVAINE ${ }^{1}$, Ana Luisa Martins ROSA ${ }^{1}$, \\ Ana Beatriz Tozzo MARTINS², Rute Grossi MILANI ${ }^{1,3 *}$ \\ ${ }^{1}$ Programas de Pós-Graduação em Tecnologias Limpas e Promoção da Saúde, Centro Universitário de Maringá, Maringá, PR, Brasil. \\ ${ }^{2}$ Universidade Estadual de Maringá (UEM), Maringá, PR, Brasil. \\ ${ }^{3}$ Instituto Cesumar de Ciência, Tecnologia e Inovação (ICETI), Maringá, PR, Brasil. \\ *E-mail de contato: rute.milani@unicesumar.edu.br
}

Artigo recebido em 5 de janeiro de 2016, versão final aceita em 7 de junho de 2016.

RESUMO: Este estudo buscou analisar o perfil de consumo e o destino pós-consumo das tecnologias digitais por jovens. Participaram da pesquisa 404 jovens, com idades entre 15 e 24 anos. Aplicou-se um questionário estruturado sobre as motivações para o uso, os motivos das trocas e os tipos de descarte. A análise estatística, efetuada por meio de regressão logística, mostrou que o gênero masculino tem $51 \%$ mais chance de troca da tecnologia de informática por desatualização do que o feminino. Além disso, o gênero feminino tem 2,44 vezes mais chances de trocar a tecnologia de telefonia por beleza. Quanto ao descarte, os jovens possuem a tendência de guardar, evidenciando o valor afetivo atribuído à tecnologia, embora o descarte em lixo comum ainda seja uma prática usual. Conclui-se que há necessidade de os jovens construírem um posicionamento crítico diante do apelo ao consumo, bem como ações de educação ambiental, visando ao comportamento ecológico.

Palavras-chave: meio ambiente; estudantes; tecnologia da informação; resíduos; saúde ambiental.

ABSTRACT: This study sought to analyze the profile of consumption and post-consumption of digital technologies by young people. Four hundred and four young people participated in the survey, aged between 15 and 24 years. A structured questionnaire about their motivations to use of technologies was applied, as well as for the reasons for exchanging them and types of disposal. Statistical analysis performed using logistic regression showed that the males have $51 \%$ more chances to exchange the computer due to outdated technology than the female. In addition, the females have 2.44 more chances to exchange technology telephony by beauty. For disposal, the youngsters have a tendency to store, highlighting the affective value attributed to technology, although disposal in regular trash is still a usual practice. It was concluded that there is the need for young people to 
build a critical position before the call to consumption, as well as environmental education, aiming ecological awareness.

Keywords: environment; students; information technology; waste; environmental health.

\section{Introdução}

No mundo on-line e interconectado, é possível encontrar grande parte do que se conhece como público, de tal modo que as páginas dos jornais e os meios de transmissões das informações foram substituídos. Hoje, a sociedade midiática é virtual e percorre milhares de computadores, tablets e celulares. Por consequência, um dos setores industriais que tem aumentado significativamente é a produção de equipamentos elétricos e eletrônicos, impulsionada pela inovação tecnológica e pelos padrões de consumo do mundo atual. Simultaneamente a essa demanda, há um aumento da geração de resíduos desses equipamentos no meio ambiente, o que ocasiona a contaminação ambiental e agravos à saúde humana (Mucelin \& Bellini, 2008; Giaretta et al., 2010).

Em 2014, a Organização das Nações Unidas (ONU) anunciou um descontrole da gestão de eletroeletrônicos na América do Sul. Só no Brasil, a produção de lixo eletrônico foi de 1,4 milhão de toneladas e, mundialmente, a estimativa de produção de lixo eletrônico remete a níveis econômicos altos, sendo produzidos por ano 41 milhões de toneladas desses resíduos (Nações Unidas do Brasil, 2015). Explorar a maneira que o indivíduo se relaciona com a tecnologia, englobando o consumo e o descarte, consiste em uma necessidade nesse cenário alarmante.

$\mathrm{O}$ uso das tecnologias digitais se dá precocemente pelo sujeito, por meio do encantamento que estas proporcionam, pela autoafirmação e pelo status social que simbolizam (Balbani \& Krawczyk, 2011). Além dos fatores sociais, Spizzirri et al. (2012) apontam que o uso da internet ocorre na primeira infância de forma autônoma, destacando a falta de participação dos pais no processo de aprendizagem tecnológica pelos seus filhos. As crianças nascidas entre 1980 e 1994 passaram a ser consideradas nativas digitais ou geração interativa, visto que utilizam as novas mídias, como a internet, os celulares e outros dispositivos eletrônicos integrados ao cotidiano (Passarelli et al., 2014). Segundo Almeida (2000) apud Rocha (2008), o computador tornou-se um aparelho indispensável na sociedade atual. Ele pode ser definido como uma máquina de teste de ideias e hipóteses voltada para a criação de um mundo abstrato e simbólico, a qual introduz diferentes formas de atuação e interação entre os usuários, assumindo diferentes funções. Como instrumento de trabalho, ele contribui para o aumento da produtividade, a diminuição de custos e a qualidade dos serviços; por outro lado, como instrumento de entretenimento, suas possibilidades são diversas.

Entretanto, a ascensão do comportamento de compra de aparelhos digitais sofre influências cultural, ideológica, afetiva ou modista, de modo que a explicação para esse fato está além da dimensão consciente e do controle do sujeito (De Lima, 2011). Segundo Conceição et al. (2014), as pessoas têm apresentado um comportamento de consumo das tecnologias digitais não somente utilitário, mas que agrega parte da expressão pessoal. As pessoas agora consomem pela emoção e sentimentos associados e não apenas pela real necessidade de uso. 
O mercado tecnológico tem sido cada vez mais exigente e não basta um produto ser bom: ele deve ser bonito e ter um design que chame a atenção. A multifuncionalidade dos aparelhos celulares, tais como o acesso à internet, televisão, MP3, câmera digital e outros serviços adicionais, tem por característica engrandecer e diferenciar os usuários, permitindo a ampliação do consumo e a busca de novas perspectivas para diferentes produtos. Além dessas características, em geral os consumidores já desejaram o produto antes de seu lançamento, pois, somado aos serviços para os quais é utilizado, permite o prazer e a satisfação, bem como o status social (Arruda Filho et al., 2008).

O aparelho celular tem papel significativo para a variabilidade social, ou seja, o dispositivo permite a expressão de singularidade e identificação, favorecendo a formação de grupos que compartilham e se conectam a um estilo de consumo característico da sociedade contemporânea (Silva, 2007). Nicolaci-da-Costa (2004) afirma que os jovens demonstram uma intensa necessidade de permanecerem disponíveis, mantendo o celular próximo e atualizado, com o objetivo de cessar a curiosidade e de não perder a informação dinâmica das redes sociais, porém, quando ficam sem o aparelho, o sentimento de perda é inerente, distanciando-os da conexão com o mundo.

Segundo Conceição et al. (2014), a substituição das antigas tecnologias por novas pode ser resultado da obsolescência programada, que consiste no ato de o fabricante interromper ou programar a vida útil de um determinado produto intencionalmente. Esse fato, concomitantemente à ação do marketing, pode ser considerado uma redução gradativa imposta, ou seja, há uma expectativa de que o produto dure determinado período e seja posteriormente substituído. A obsolescência programada é um fenômeno contrastante no cenário tecnológico. Além dos avanços de componentes e modelos mais atraentes no mercado, a premissa de softwares novos e atualizados marca um rompimento do uso de aparelhos antigos, ou seja, produtos em bom estado tendem a ficar ultrapassados por atualizações inviabilizadas para modelos antigos (Weerasuriya \& Wyjayanayake, 2014). Ban (2004) apud Giaretta et al. (2010) destaca que o consumidor utiliza seu aparelho celular em média por 18 meses antes de descartá-lo, tornando, assim, o consumo uma constante.

Entretanto, a velocidade de produção de novos aparelhos é contrária à de implementação de políticas públicas dirigidas ao setor de infraestrutura em coleta e encaminhamento para a recuperação ou tratamento desses resíduos. Além disso, segundo Pato (2005), as pesquisas que envolvem a temática ambiental e a participação de grupos ambientalistas e da sociedade civil em campanhas que buscam a conscientização e a proteção do meio ambiente não têm alcançado seus resultados esperados.

Nas cidades, os hábitos e a cultura de consumo de produtos industrializados resultam na produção exagerada de lixo e, dependendo da forma com que esses resíduos são tratados ou descartados no meio ambiente, podem gerar agressões ao contexto urbano, além de afetar regiões rurais (Mucelin \& Bellini, 2008).

O lixo eletrônico consiste em resíduos tecnológicos, de uso pessoal ou organizacional, caracterizados por eletrônicos que se tornaram obsoletos diante dos avanços tecnológicos iminentes. Portanto, a produção crescente de lixo eletrônico evidencia o comportamento dos usuários das tecnologias digitais, que se caracteriza pelo consumo cada vez mais acentuado desses produtos (Da Silva, 2010).

$\mathrm{O}$ descarte inadequado das tecnologias vem causando diversas preocupações devido ao excedente de produtos em aterros ou lixões, compostos 
de múltiplos elementos, tais como metais pesados e tóxicos, plástico, vidro e outros materiais, que apresentam riscos ao meio ambiente e à saúde humana (Lima et al., 2015). Até a década de 90, não era cogitada no Brasil a questão da contaminação ambiental por pilhas e baterias usadas, nem mesmo pelas novas tecnologias (Reidler \& Günther, 2003). Entre os resíduos de equipamentos elétricos e eletrônicos descartados atualmente, os aparelhos provenientes da área de tecnologia de telefonia, categoria em que se enquadram os aparelhos de telefonia móvel, são os predominantes.

Novas práticas de uso operacional das tecnologias da informação (TI) são incentivadas por gestores, denominadas de TI verde. O principal motivador para essa mudança é o fator econômico, o que viabiliza às empresas benefícios diretos $\mathrm{e}$ indiretos, como a redução de resíduos, economia de recursos em setores industriais e o atrativo comercial da sustentabilidade (Lunardi et al., 2014). Conforme argumentam Rodrigues \& Colesanti (2008), a tecnologia pode se constituir um meio emancipatório de promoção do comportamento ecológico, pois, diante da crise ambiental vinculada a modelos de produção e consumo exacerbados, a informação é um meio que favorece a implementação de valores ecológicos na sociedade.

O comportamento ecológico é um dos principais temas da psicologia ambiental e integra as atitudes ambientais e a intencionalidade de proteção ao ambiente. A partir dessa perspectiva, devem-se enfatizar os ambienteis físicos, sociais e econômicos em que o indivíduo está inserido, a fim de compreender suas ações e sua percepção do ambiente (Pato \& Campos, 2011).

A presente pesquisa teve por objetivo analisar os motivos para a troca e as formas de descarte das tecnologias digitais por jovens. Como objetivos específicos, buscou-se caracterizar o perfil de con- sumo das tecnologias digitais, assim como analisar o comportamento de descarte das tecnologias em desuso. $\mathrm{O}$ estudo foi direcionado para estudantes entre 15 e 24 anos, matriculados em uma instituição particular de ensino, localizada na região noroeste do Estado do Paraná, por meio de um estudo exploratório. Silva \& Oliveira (2010) argumentam que cabe às instituições educacionais o papel de atuarem como espaço de desenvolvimento da cultura e socialização, pois estes locais têm natureza vinculada ao futuro, o que os torna propícios para discussões de questões ambientais.

O artigo possui, além desta introdução, a seção sobre a metodologia empregada, englobando a perspectiva de um estudo exploratório e o emprego de análises dos resultados por regressão logística. Em seguida, os resultados são apresentados, tendo-se como enfoque o comportamento de consumo e o descarte das tecnologias digitais por jovens. Posteriormente, é realizada a discussão desses resultados, enfatizando as dinâmicas vinculadas entre o sujeito e as tecnologias digitais.

\section{Desenvolvimento}

\subsection{Participantes}

A presente pesquisa, de caráter exploratório e transversal, contou com a participação de 404 jovens de ambos os sexos, entre 15 e 24 anos, estudantes do $3^{\circ}$ ano do ensino médio e do $1^{\circ}$ ano do ensino superior, matriculados em duas instituições privadas, situadas no município de Maringá - Paraná. Com relação ao ensino superior, consideraram-se os alunos matriculados nos primeiros anos dos cursos de Psicologia, Direito, Administração, Engenharia Mecânica e Análise e Desenvolvimento de Sistemas. A Tabela 1 apresenta a caracterização desses jovens. 
TABELA 1 - Características sociodemográficas dos jovens.

\begin{tabular}{cccc}
\hline Variável & Categoria de resposta & N & \% \\
\hline \multirow{2}{*}{ Gênero } & Masculino & 173 & 42 \\
& Feminino & 231 & 58 \\
Idade & 15 a 19 & 252 & 62 \\
Escolaridade & 20 a 25 & 152 & 38 \\
Ensino Médio & Feminino & 26 & 59 \\
& Masculino & 18 & 41 \\
& & & \\
Graduação & Feminino & 206 & 57 \\
& Masculino & 154 & 43 \\
\hline
\end{tabular}

FONTE: Elaborada pelos autores

Pode-se observar pela Tabela 1 que mais de $60 \%$ dos participantes possui idade entre 15 e 19 anos. Este dado se justifica pelo delineamento do presente estudo, que considera os alunos matriculados no $1^{\circ}$ ano do curso superior, o qual é formado principalmente por jovens que acabaram de concluir o ensino médio, portanto, adolescentes, os quais estão passando pela transição da adolescência para a fase adulto jovem.

\subsection{Instrumentos e materiais}

Para a coleta de dados, foi aplicado um questionário contendo 20 questões sobre os seguintes aspectos: as motivações para o uso, os motivos das trocas dos aparelhos e os tipos de descarte realizados. Como motivos de troca, considerou-se o fato de os aparelhos se encontrarem nas seguintes categorias: "Feio", "Velho", "Desatualizado" e "Quebrado", para os quais foram atribuídos valores iguais a "1" para uma resposta assinalada e "0" (zero) caso contrário.

Os participantes poderiam responder a mais de uma alternativa por questão, o que pode implicar em um percentual superior a $100 \%$ nos resultados.
Para melhor compreensão dos dados, as tecnologias digitais foram categorizadas em tecnologias digitais de informática, compostas por computadores e notebooks, e tecnologias digitais de telefonia, caracterizadas pelos smartphones e aparelhos celulares. Foram excluídas as tecnologias do tipo tablet, ipod, $m p 3, m p 4$, pois as funções tecnológicas também podem estar presentes nos aparelhos considerados neste estudo.

\subsection{Procedimento de coleta de dados}

Este estudo transcorreu no primeiro semestre de 2013, mediante a apreciação e a aprovação junto ao Comitê de Ética da instituição, sob o parecer $n^{\circ}$ 379.115. A aplicação do questionário foi realizada em sala de aula, após esclarecimento dos objetivos da pesquisa, destacando-se o sigilo em relação aos dados e garantindo a liberdade de escolha do participante em responder ou não. Para os menores de 18 anos, solicitou-se aos pais ou responsáveis, previamente, a assinatura do termo de consentimento livre e esclarecido. O tempo médio de coleta de dados foi de aproximadamente 20 minutos, sendo realizada no início ou final das aulas.

\subsection{Procedimento de Análise dos dados}

Inicialmente, fez-se uma análise exploratória dos dados com a elaboração de tabelas de frequências. Em seguida, ajustou-se o seguinte modelo de regressão logística:

$\log i t(p)=\ln \left(\frac{p}{1-p}\right)=\beta_{0}+\beta_{1} X$ (3) em que $p=$ $P(Y=1)$ é a probabilidade de que a troca da tecnologia ocorra por cada um dos motivos $(Y)$ acima relacionados e $1-p=P(Y=0)$ é a probabilidade da 
não ocorrência dessa troca. Como variáveis explicativas do modelo, consideraram-se o gênero, a idade e a escolaridade.

A análise de regressão logística foi feita utilizando-se o ambiente estatístico R (R Development Core Team, 2014) e o nível de significância $(\alpha)$ adotado foi igual a $5 \%$.

\section{Resultados}

Com base nos dados coletados por meio da aplicação dos questionários, apresentam-se, inicialmente, os percentuais dos principais motivos que levaram os jovens a fazerem a troca de suas tecnologias digitais de informática e de telefonia. Em seguida, são descritos os resultados do ajuste do modelo de regressão logística para a categoria motivo de troca. Para finalizar, apresentam-se os percentuais de resposta correspondente à destinação de equipamentos, baterias e suplementos, tais como $\mathrm{CD}$, DVD, disquete, pen drive e fone de ouvido após o uso.
A Tabela 2 apresenta a distribuição do percentual de jovens em relação ao tipo de aparelho e o motivo da troca das tecnologias digitais de informática e telefonia.

TABELA 2 - Percentual de respostas dos jovens segundo o tipo de tecnologia e o motivo da troca.

\begin{tabular}{lcc}
\hline Motivo de troca & Informática & Telefonia \\
\hline Ficou Feio & 07 & 25 \\
Ficou Velho & 46 & 58 \\
Ficou Desatualizado & 52 & 76 \\
Quebrou & 33 & 58 \\
\hline
\end{tabular}

FONTE: elaborado pelos autores.

Considerando os motivos que levaram os jovens a trocarem suas tecnologias digitais, a maior frequência é encontrada para a categoria "ficou desatualizado", seguida por "ficou velho" e "quebrou". Logo em seguida, foi realizado um modelo de regressão logística, o qual foi ajustado considerando as variáveis independentes idade, sexo e escolaridade, sendo que somente para sexo o modelo foi significativo. Os resultados são apresentados na Tabela 3.

TABELA 3 - Estimativas dos parâmetros do modelo de regressão logística com respectivos valores $p$ e estimativas de odds ratio e limites de $95 \%$ de confiança, considerando o sexo como variável independente.

\begin{tabular}{|c|c|c|c|c|c|c|c|}
\hline Motivo de Troca & $\hat{\beta}_{0}$ & Valor $p_{\hat{\beta}_{0}}$ & $\hat{\beta}_{1}$ & Valor $p_{\hat{\beta}_{1}}$ & $O R$ & $L I$ & $L S$ \\
\hline \multicolumn{8}{|l|}{ Informática } \\
\hline Velho & $-0,22$ & 0,1498 & 0,13 & 0,5355 & 1,13 & 0,76 & 1,68 \\
\hline Desatualizado & 0,48 & 0,0020 & $-0,72$ & 0,0005 & 0,49 & 0,33 & $0,73^{*}$ \\
\hline \multicolumn{8}{|l|}{ Telefonia } \\
\hline Feio & $-1,64$ & $<0,0001$ & 0,89 & 0,0004 & 2,44 & 1,50 & $3,98^{*}$ \\
\hline Velho & 0,03 & 0,8196 & 0,51 & 0,0132 & 1,66 & 1,11 & $2,48^{*}$ \\
\hline Desatualizado & 0,93 & $<0,0001$ & 0,38 & 0,0998 & 1,47 & 0,93 & 2,32 \\
\hline Quebrado & 0,10 & 0,4940 & 0,40 & 0,0501 & 1,49 & 1,00 & 2,23 \\
\hline
\end{tabular}

FONTE: elaborado pelos autores

NOTA: * Significativo, pois o intervalo de confiança não contém o valor 1. 
Observa-se que os parâmetros do modelo foram significativos a um nível de 5\% de significância para os motivos de troca de tecnologia de informática desatualizada e para o aparelho de telefonia feio. Por outro lado, pode-se afirmar que para o aparelho de telefonia o logaritmo da probabilidade de troca por estar velho em relação à não troca aumenta a uma taxa de 0,51 quando o jovem é do sexo feminino.

Pode-se afirmar, inclusive, que o gênero masculino tem $51 \%$ vezes mais chance de troca por desatualização do que o feminino em relação à tecnologia de informática. Entretanto, o gênero feminino tem 2,44 vezes mais chances de trocar a tecnologia de telefonia por beleza e 1,66 vezes mais chances por estar velho do que o gênero masculino.

Os dados relativos à destinação de equipamentos e baterias são apresentados na Tabela 4 .

TABELA 4 - Percentual de respostas segundo a destinação de equipamentos e baterias e o tipo de tecnologia.

\begin{tabular}{lcc}
\hline Destinação & Informática & Telefonia \\
\hline Guardou & 43 & 65 \\
Devolveu à loja & 04 & 03 \\
Vendeu & 26 & 30 \\
Descartou em lixo comum & 10 & 22 \\
Descartou em lixo reciclado & 13 & 16 \\
Perdeu & 03 & 25 \\
Deu a outra pessoa & 29 & 42 \\
\hline
\end{tabular}

FONTE: Elaborado pelos autores.

Verifica-se na Tabela 4 o percentual de respostas quanto à destinação de equipamentos e baterias das tecnologias digitais a partir do momento em que são consideradas inadequadas pelo sujeito.

É possível identificar que a maior parte dos jovens apresentou o comportamento de guardar suas tecnologias, tanto de informática como de telefonia, seguido pelo comportamento de dar a outra pessoa, ou vender. Vale ressaltar que alguns jovens assinalaram que descartam suas tecnologias em lixo comum e em lixo reciclado, e um número baixo de jovens assinalou o comportamento de devolver à loja suas tecnologias não mais utilizáveis.

TABELA 5 - Percentual de resposta quanto à destinação de suplementos de tecnologia.

\begin{tabular}{cccccc}
\hline Destinação & CD & DVD & Disquete & $\begin{array}{c}\text { Pen } \\
\text { drive }\end{array}$ & $\begin{array}{c}\text { Fone de } \\
\text { ouvido }\end{array}$ \\
\hline Guardou & 58 & 52 & 23 & 57 & 46 \\
$\begin{array}{c}\text { Descarte em Lixo } \\
\text { Comum }\end{array}$ & 35 & 31 & 27 & 10 & 37 \\
$\begin{array}{c}\text { Descarte em Lixo } \\
\text { Reciclado }\end{array}$ & 12 & 10 & 11 & 04 & 08 \\
\hline
\end{tabular}

FONTE: Elaborado pelos autores.

Em relação à destinação de suplementos de tecnologias (Tabela 5), constata-se que, além do comportamento de guardá-los, assim como no caso dos equipamentos, os jovens também apresentaram o comportamento de descarte em lixo comum e, com um percentual inferior, o comportamento de descarte em lixo reciclado.

\section{Discussão}

Ao se analisar os motivos que levaram os jovens a trocar as tecnologias digitais, observou-se que a troca se deu principalmente por estarem desatualizadas, velhas ou quebradas. Esses dados corroboram o estudo de Silva (2007), em que a compra de um novo aparelho tecnológico pelo jovem é justificada mais pelo interesse no design do que pelos elementos instrumentais, de modo que os aparelhos são percebidos por eles como um meio de diferenciação do grupo. A partir dos dados levantados com os jovens neste estudo, foi possível identificar que ocorre a troca de aparelhos em consequência do lançamento de um novo modelo, por mais que a funcionalidade do novo comparada à do antigo ainda seja semelhante, portanto, há grande 
influência do ambiente social, cultural, econômico e tecnológico para o consumo desses dispositivos (Silva, 2007; Weerasuriya \& Wyjayanayake, 2014). Silva (2007) ressalta que as tecnologias digitais muitas vezes são vistas como um utensílio da moda, razão pela qual os jovens possuem a necessidade de exibi-lo para os outros.

Por outro lado, Conceição et al. (2014) argumentam que a troca de produtos antigos por novos recém-lançados no mercado consumidor não acontece somente no contexto dos aparelhos eletrônicos, pois as pessoas têm trocado automóveis, casas e aparelhos eletrodomésticos com uma velocidade cada vez mais crescente. Dessa forma, pode-se sugerir que os consumidores se determinam a comprar as novas tecnologias, mesmo que não tenham necessidade ou que não atendam as suas expectativas, além de ser mais fácil comprar o novo do que arrumar o velho. Os aparelhos eletrônicos deixaram de fazer parte da categoria de utilitários para serem incorporados como uma forma de expressão visual ou parte do vestuário, gerando a necessidade de mostrar aos outros o produto de ponta adquirido (Conceição et al., 2014).

Visto que a população estudada foi a de estudantes com idade entre 15 e 24 anos, destaca-se que eles possuem valores e tendências semelhantes por estarem, constantemente, buscando definir sua identidade e amadurecimento psíquico a partir da necessidade de aceitação em determinado grupo (Mota \& Rocha, 2012). Rosado \& Tomé (2015) afirmam que os jovens nativos digitais mantêm a conectividade para mediar a comunicação com seus pares, saciando suas necessidades de interação e convivência em grupo. Dessa maneira, as tecnologias digitais contribuem para suprir essas necessidades de ser aceito e de independência. Neste estudo, constatou-se que a troca da tecnologia de telefonia deu-se principalmente, no gênero feminino, por motivo de beleza e, para o gênero masculino, por estar velho. Tais dados demonstram que determinados valores estão arraigados no comportamento dos jovens, o que sinaliza uma contradição em relação à problemática ambiental. Conceição et al. (2014) salientam que a classe social urbana e metropolizada tem se associado com as tecnologias de tal forma que foi permida a criação de novos perfis de consumo e descarte aceitos e não questionados. Conforme apontado anteriormente neste estudo, os jovens relataram que a aparência do produto é um fator que possui grande influência para o consumo, o que contribui para tal perfil.

Os dados que se referiram à destinação de equipamentos e baterias das tecnologias digitais, a partir do momento em que eram consideradas desnecessárias pelo sujeito, sugerem que os jovens tendem, predominantemente, a guardar suas tecnologias digitais de informática e de telefonia para uma possível necessidade futura ou por não conseguirem se desfazer de um bem material que foi conquistado com esforço. De Lima (2011) afirma que todas as pessoas guardam coisas e objetos, seja por considerá-los necessários, por serem vistos como relíquias ou por possuírem um apego associado a um investimento afetivo. Foi possível identificar também, entre os jovens pesquisados, o comportamento de doar e de vender as tecnologias digitais, o que evidencia que, por mais que os jovens sempre busquem as novidades, eles também se importam com o reaproveitamento desses equipamentos, seja por um motivo econômico ou para colaborar com a inclusão digital, pois esses equipamentos serão repassados para entidades, creches e programas sociais (Silva et al., 2013).

No entanto, observou-se, neste estudo, que ainda existe a prática de descarte das tecnologias em lixo comum, o que chama a atenção, já que, segundo Reidler \& Günther (2003), são encontrados metais 
pesados em computadores e baterias de aparelhos celulares, os quais são caracterizados por conterem componentes nocivos à saúde, podendo causar efeitos nos sistemas nervoso e sanguíneo e em órgãos vitais, como o fígado, os rins e os pulmões. O descarte no lixo comum pode ser compreendido pela falta de informações sobre tais riscos à saúde humana e ambiental, ou por carência de alternativa adequada. Assim, já que apenas a informação não leva por si só à produção de alterações significativas no comportamento de descarte apropriado às tecnologias, a falta de coletores específicos é um demonstrativo de carência de estratégias de combate a este comportamento (Giaretta et al., 2010; Nações Unidas do Brasil, 2015). Em relação aos suplementos da tecnologia, foi possível identificar que o número de jovens que assinalaram terem realizado o descarte em lixo comum foi maior do que aqueles que responderam ter descartado em lixo reciclado, o que se pode associar à cultura do consumismo, que, de acordo com Mucelin \& Bellini (2008), está presente nas cidades e contribui para a geração de lixo. Os autores afirmam, ainda, que a maioria das cidades brasileiras tem o hábito de descartar o lixo de forma errônea, amontoando os materiais sem utilidade em locais inadequados, como fundos de vales, margens de estradas e terrenos baldios.

É importante destacar que os jovens possuem uma singularidade no que diz respeito à aquisição de comportamento ecológico, pois sua conduta coletiva e sua formação de identidade evidenciam uma força emancipatória. A motivação intrínseca e a experiência coletiva por meio de pares são variáveis que podem estimular a conduta pró-ambiental (Tabernero \& Hernández, 2011; Matthies et al., 2012).

Em contrapartida, deve-se considerar que a cultura do consumismo contribui para o avanço tecnológico acelerado, o qual tem diminuído o ciclo de vida esperado dos equipamentos, tornando-os desatualizados a cada novo lançamento (Mattos et al., 2008). Neste estudo, observou-se que o lixo tecnológico, com frequência, não tem um destino adequado, o que pode ser explicado, segundo os autores, como consequência da não orientação efetiva à população sobre como suas tecnologias devem ser descartadas, visto que inicialmente a área da informática não era relacionada como potencial indústria de poluição.

Uma proposta frente ao descarte inadequado dos lixos eletrônicos é alinhar as políticas públicas em integração com a participação do cidadão. $\mathrm{O}$ reuso e a reciclagem de tecnologias podem ser incrementados em criações artísticas ou programas de educação ambiental, incentivando as dimensões imaginativas e criativas na construção de uma nova relação entre homem e tecnologia (Jackson \& Kang, 2014). Remy \& Huang (2015) afirmam que a escassez de recursos naturais e as mudanças de padrões de consumo podem delimitar novas metas industriais frente à obsolescência programada, exigindo uma perspectiva alinhada ao desenvolvimento sustentável.

Os resultados desta pesquisa sinalizam dificuldades no desenvolvimento do comportamento ecológico entre os jovens, o que é observado pela forma como utilizam e descartam suas tecnologias. De acordo com essa perspectiva, Coelho et al. (2006) argumentam que a psicologia ambiental, por meio do estudo de valores, atitudes e crenças ambientais, pode contribuir para mudanças comportamentais significativas. As tecnologias digitais estão diretamente relacionadas ao status social que trazem ao indivíduo que as utiliza, levando os sujeitos a consumirem sem necessidade. Elas são muito utilizadas pelos jovens, pois suprem a necessidade que eles têm de serem aceitos por seus grupos. Porém, o mau uso dessas tecnologias, associado ao descarte inadequado, revela a ausência 
de comprometimento com as questões ambientais, pois se percebe que ainda é baixa a preocupação acerca dos resíduos que esse consumo gera e aos problemas ambientais associados.

\section{Considerações finais}

Este estudo buscou analisar o perfil de consumo das tecnologias digitais por jovens, bem como o comportamento pós-consumo apresentado por eles. A maioria dos jovens pesquisados demonstrou que os principais motivos para a troca de suas tecnologias digitais são a desatualização e a obsolescência, principalmente com relação às tecnologias de telefonia, como celulares e smartphones. Quanto à destinação das tecnologias digitais pós-uso, foi encontrado um grande número de jovens que apresentou o comportamento de guardar suas tecnologias e equipamentos. É possível observar que gradativamente eles têm se tornado acumuladores, seja pela falta de informações adequadas de como proceder no descarte, seja pela dificuldade de desligar-se de um objeto que ainda está em condições de uso e que pode ser necessário futuramente.

Ressalta-se que, paralelamente ao comportamento de guardar, os jovens também relataram descartar as tecnologias digitais em lixo comum. Embora este comportamento seja menos frequente, é preocupante, visto que o jovem demonstrou não ter consciência da forma de descarte adequada, bem como das consequências que as substâncias presentes nessas tecnologias podem causar à saúde e ao ambiente.

Os participantes deste estudo foram os jovens estudantes da rede privada de ensino, o que limita a generalização dos dados e sugere a importância de se estudar a relação de consumo em interface com os fatores sociais, econômicos e demográficos. Outra limitação é que a amostra de jovens pesquisada está iniciando sua formação, portanto, é necessário verificar posteriormente se o conhecimento obtido durante a graduação pode promover o comportamento ecológico. A delimitação dos jovens como um público-alvo trouxe também questionamentos sobre o uso das tecnologias que remetem à infância e outras fases do desenvolvimento humano, como a adultez e a terceira idade. Por esse motivo, recomendam-se pesquisas em crianças, considerando que estas já recebem a educação ambiental na escola e têm acesso cada vez maior ao brincar digital. Quanto aos adultos, por estarem plenamente imersos no uso das tecnologias digitais no contexto de trabalho, será que estão comprometidos com o uso sustentável das tecnologias? Já em relação à terceira idade, por ter sido gradativamente inserida no universo tecnológico, ainda se tem que explorar as possibilidades de promoção da saúde e bem-estar dessas tecnologias, bem como o seu potencial para compartilhar saberes entre gerações, especialmente o que se refere ao cuidado com o ambiente. Portanto, faz-se necessário estudar as fases do desenvolvimento humano para ter uma visão ampla sobre o uso dessas tecnologias nos diferentes grupos.

O questionário aplicado também apresentou limitações por não permitir avaliar valores, já que os participantes poderiam assinalar mais de uma opção, tendo suas respostas classificadas em mais de uma categoria. Além disso, este não avaliou variáveis relacionadas ao comportamento ecológico. Deste modo, sugerimos para pesquisas futuras a associação com instrumentos ecológicos.

A amostra utilizada neste estudo, devido ao seu tamanho, trouxe como vantagem a possibilidade de fazer uma análise transversal sobre o comportamento de consumo das tecnologias digitais em jovens estudantes. Novas pesquisas podem ser feitas por meio do estudo longitudinal, no qual poderia ser avaliado de que forma se dá a relação entre os jovens e as tec- 
nologias, bem como verificar o impacto das medidas de conscientização utilizadas pela mídia e escolas em relação ao descarte e ao uso das tecnologias.

Para finalizar, conclui-se que há necessidade de ações de educação ambiental junto aos jovens, visando promover a sensibilização ambiental e que levem a atitudes pró-ambientais, ligadas à conscientização da necessidade de proteção do meio ambiente, já que eles podem estar demonstrando uma não consciência de seus comportamentos.

\section{Referências}

Arruda Filho, E. J. M.; Cabusas, J. J.; Dholakia, N. Fator social versus tecnologia utilitária: marketing social versus mercado utilitário. JISTEM, 5(2), 305-324, 2008. doi: 10.4301/S1807-17752008000200006

Balbani, A. P. S.; Krawczyk, A. L. Impacto do uso do telefone celular na saúde de crianças e adolescentes. Revista Paulista de Pediatria, 29(3), 430-6, 2011. doi 10.1590/ S0103-05822011000300019

Coelho, J. A. P. de M.; Gouveia, V. V.; Milfont, T. L. Valores humanos como explicadores de atitudes ambientais e intenção de comportamento pró-ambiental. Psicologia em Estudo, 11(1), 2006. doi: 10.1590/S1413-73722006000100023

Conceição, J. T. P.; Conceição, M. M.; Araújo, P. S. L. Obsolescência programada - tecnologia a serviço do capital. In: Anais do Congresso Virtual Brasileiro de Administração. São Paulo, 23 de nov., 2014. Disponível em: <http://www. convibra.com.br/upload/paper/2013/28/2013_28_5565. pdf>.

Da Silva, J. R. N. Lixo eletrônico: um estudo de responsabilidade ambiental no contexto do Instituto de Educação, Ciência e Tecnologia do Amazonas - IFAM, Campus Manaus Centro. In: Anais do Congresso Brasileiro de Gestão Ambiental. Bauru, 21 de nov., 2010. Disponível em: $<$ http:// www.senept.cefetmg.br/galerias/Anais_2010/Posteres/ GT06/LIXO_ELETRONICO.pdf $>$.

De Lima, R. Acumuladores compulsivos: uma nova patologia psíquica. Revista Espaço Acadêmico, 2011. Disponível em: <http://www.periodicos.uem.br/ojs/index.php/EspacoAcademico/article/view/15203 > . Acesso em: mar. 2015.

Giaretta, J. B. Z.; Tanigushi, D. G.; Sergent, M. T.; Vasconcellos, M. P.; Günther, W. M. R. Hábitos relacionados ao descarte pós-consumo de aparelhos e baterias de telefones celulares em uma comunidade acadêmica. Saúde e Sociedade, 19(3), 674-684, 2010. doi: 10.1590/S010412902010000300018

Jackson, S. J.; Kang, L. Breakdown, obsolescence and reuse: $\mathrm{HCI}$ and the art of repair. In: Proceedings of the SIGCHI Conference on Human Factors in Computing Systems. New York, 4 abr. 2014. doi 10.1145/2556288.2557332

Lima, A. F. O.; Sabiá, R. J.; Teixeira, R. N. P.; Júnior, F. A. V. S. Gestão de resíduos eletroeletrônicos e seus impactos na poluição ambiental. Latin American Journal of Business Management, 6(2), 109-126, 2015. Disponível em: <http:// www.lajbm.net/index.php/journal/issue/view/12>.

Lunardi, G. L.; Simões, R.; Frio, R. S. TI verde: uma análise dos principais benefícios e práticas utilizadas pelas organizações. Revista Eletrônica de Administração, 20(1), 1-30, 2014. doi: 10.1590/S1413-23112014000100001

Matthies, E.; Selge, S.; Klöckner, C. A. The role of parental behaviour for the development of behaviour specific environmental norms - the example of recycling and reuse behaviour. Journal Article, 32(1), 277-284, 2012. doi: 10.1016/j.jenvp.2012.04.003

Mattos, K. M. C.; Mattos, K. M. C.; Perales, W. J. S. Os impactos ambientais causados pelo lixo eletrônico e o uso da logística reversa para minimizar os efeitos causados ao meio ambiente. In: Anais do Encontro Nacional de Engenharia de Produção. Rio de Janeiro, 13 de out., 2008. Disponível em: <http://www.abepro.org.br/biblioteca/enegep2008_TN_STP_077_543_11709.pdf >.

Mota, C. P.; Rocha, M. Adolescência e jovem adultícia: crescimento pessoal, separação-individuação e o jogo das relações. Psicologia: Teoria e Pesquisa, 28(3), 357-366, 2012. doi: 10.1590/S0102-37722012000300011

Mucelin, C. A.; Bellini, M. Lixo e impactos ambientais perceptíveis no ecossistema urbano. Sociedade \& Natureza, 
20(1), 111-124, 2008. Disponível em: <http://www.scielo. br/pdf/sn/v20n1/a08v20n1>.

Nações Unidas do Brasil. Brasil produziu 1,4 milhão de toneladas de resíduos eletrônicos em 2014, afirma novo relatório da ONU, 2015. Disponível em: $<$ https://nacoesunidas. org/brasil-produziu-14-milhao-de-toneladas-de-residuos-eletronicos-em-2014-afirma-novo-relatorio-da-onu/>. Acesso em: abr. 2016.

Nicolaci-da-Costa, A. M. Impactos psicológicos do uso de celulares: uma pesquisa exploratória com jovens brasileiros. Psicologia: Teoria e Pesquisa, 20(2), 165-174, 2004. doi: 10.1590/S0102-37722004000200009

Passarelli, B.; Junqueira, A. H.; Angeluci, A. C. B. Os nativos digitais no Brasil e seus comportamentos diante das telas. MATRIZes, 8(1), 159-178, 2014. Disponível em: $<$ http://www.matrizes.usp.br/index.php/matrizes/article/ viewFile/404/pdf $>$.

Pato, C. Comportamento ecológico: chave para compreensão e resolução da degradação ambiental? Democracia Viva, 27, 102-107, 2005.

Pato, C. M. L.; Campos, C. B. Comportamento ecológico. In: Cavalcante, S.; Elali, G. Temas básicos em psicologia ambiental. Petrópolis, Vozes, 2011.

$\mathrm{R}$ Development Core Team. $R$ : a language and environment for statistical computing, R Foundation for Statistical Computing. Vienna, Austria, 2014. Disponível em: $<$ http:// www.R-project.org>.

Reidler, N. M. V. L.; Günther, W. M. R. Impactos ambientais e sanitários causados por descarte inadequado de pilhas e baterias usadas. Revista Limpeza Pública, 60(1), 20-26, 2003. Disponível em: <http://www.mma.gov.br/port/conama/ processos/0330EB12/ImpactosAmbientaisSanitarios.doc $>$.

Remy, C.; Huang, E. M. Limits and sustainable interaction design: Obsolescence in a future of collapse and resource scarcity. First Monday, 20(8), 2015. doi: 10.5210/ fm.v20i8.6122

Rocha, S. S. D. O uso do computador na educação: a informática educativa. Revista Espaço Acadêmico, 2008. Disponível em: <http://www.espacoacademico.com. br/085/85rocha.htm>. Acesso em: mar. 2015.
Rodrigues, G. S. S. C.; Colesanti, M. D. M. Educação ambiental e as novas tecnologias de informação e comunicação. Sociedade e Natureza, 20(1), 51-66, 2008. Disponível em: <http://www.scielo.br/pdf/sn/v20n1/a03v20n1>.

Rosado, L. A. S.; Tomé, V. M. N. As redes sociais na internet e suas apropriações por jovens brasileiros e portugueses em idade escolar. Revista Brasileira de Estudos Pedagógicos, 96(242), 11-25, 2015. doi: 10.1590/S2176-6681/324612565

Silva, S. R. "Eu não vivo sem celular": sociabilidade, consumo, corporalidade e novas práticas nas culturas urbanas. In: Anais do Congresso Brasileiro de Ciências da Comunicação, Porto Alegre, 29 de ago., 2007. Disponível em: <http://www.intercom.org.br/papers/nacionais/2007/ resumos/R1736-1.pdf $>$.

Silva, L. O.; Oliveira, C. F. Professor de educação física, comunidade e espaço escolar: relações de alianças, de conflitos e de transgressões. In: Anais do Congresso Sul-Brasileiro de Ciências do Esporte. Itajaí. 23 de set., 2010. Disponível em: <http://congressos.cbce.org.br/index.php/ sulbrasileiro/vcsbce/paper/viewFile/2022/1106>.

Silva, A. F. et al. Lixo eletrônico: como dar uma melhor destinação. Revista Acadêmica FEOL, 1(1), 71-90, 2013. Disponível em: <http://feol.com.br/revista/index.php/R1/ article/view/31>.

Spizzirri, R. C. P.; Wagner, A.; Mosmann, C. P.; Armani, A. B. Adolescência conectada: mapeando o uso da internet em jovens internautas. Psicologia Argumento, 30(69), 327-335, 2012. Disponível em: <http://www2.pucpr.br/reol/pb/index. $\mathrm{php} / \mathrm{pa}$ ?dd1=5979\&dd99=

Tabernero, C.; Hernandez, B. Self-Efficacy and Intrinsic Motivation Guiding Environmental Behavior. Environmental and Behavior, 45(5), 658-675, 2011. doi: 10.1177/0013916510379759

Weerasuriya, G. T.; Wijayanayake, W. M. J. I. An Evaluation of Factors Affecting Information Systems Obsolescence. Journal of Emerging Trends in Computing and Information Sciences, 5(3), 158-164, 2014. Disponível em: <http:// www.cisjournal.org/journalofcomputing/archive/vol5no3/ vol5no3_3.pdf>. 